\title{
Surgery of otosclerosis in the Archives of The Journal of Laryngology \& Otology
}

The Archives of The Journal of Laryngology \& Otology (JLO) reveal that, in the nineteenth century, the bulk of the publication each month was taken up with reports of society proceedings and with the reproduction of lectures from individuals with names possibly better known to us today as eponyms for surgical instruments. The Archives of the JLO at that time, and certainly in its first fifty years of publication, show speakers expounding at great length and with authority on ideas regarding the pathology and treatment of common ailments, ideas which frequently seem, from a modern perspective, to be somewhat bizarre. Today, all of us who attend meetings will know how challenging it can be for any modern speaker to keep the attention of a twenty-first century audience, even with the wonders of computer presentations, embedded graphics and videos, amplification and laser pointers (a good lunch and a comfortable seat in a darkened room only too frequently combine to mitigate against giving one's undivided attention even to the best presentations). However, one hundred and fifty years ago, the writings of the time suggest that audiences were made of sterner stuff!

The short review that follows concentrates on some key articles from the last century and a half of JLO publication, in respect of the pathology and surgery of otosclerosis. The review also contains direct electronic links to the archived material quoted.

\section{'The varieties of chronic non-suppurative disease of the middle ear', D Grant (1903)} The earliest use of the term 'otosclerosis' in the journal was probably by Dundas Grant in $1903,{ }^{1}$ quoting the work of Politzer:

Otosclerosis occupies a section of its own, apparently defying classification. Politzer insists on its being distinguished from middle-ear catarrh, and accepts the designation 'otosclerosis' on account of its being currently adopted by the faculty, although he considers it more accurately described as 'capsulitis labyrinthi'. He states, however, that cases occur in which there is a combination of catarrhal adhesive processes and otosclerosis together.
However, Grant's review shows that the idea of otospongiosis as a more accurate description was already prevalent, and he refers to:

...Siebenmann's description of it as a 'spongiosirung' of the capsule of the labyrinth. It is not a disease of the ossicular articulations, but an ankylosis of the stapes with the vestibule, the result of a peculiar bone disease.

Grant is at pains to differentiate the condition from catarrhal disorders of the eustachian tube, and there is even the suggestion of the 'flamingo tint' of a Schwartze's sign. He writes:

In the sclerotic form pure and simple, there is no narrowing of the Eustachian tube, no recognisable indrawing of the tympanic membrane, nor any other visible abnormality except, in the active stage, a rosy-red crescentic area visible through the membrane, indicating a congested condition of the promontory. Politzer, who for the sake of general mutual comprehension applies to it the term 'otosclerosis', considers it best described as an osteitis of the labyrinthine capsule. Bezold considers it synonymous with 'ankylosis of the stapes', but the drawings made from his microscopical preparations show a very considerable hyperplasia of the periosteum and bone on the tympanolabyrinthine partition. Siebenmann describes the change as mainly 'spongiosirung', or what we should term a rarefying osteitis.

The natural history of the disease was clearly well understood, although the differential diagnosis might be reconsidered in modern times:

In the sclerotic form the onset is usually most insidious, and noises in the head more or less constantly worry the patient before the hearing is definitely impaired. As a rule, there is no history of distinct exacerbations after 'colds'. The patient is most often of the female sex, especially in the young cases. In many I have observed anemia and a tendency to clammy coldness of the hands and feet, such as is observed in the early stages of chronic osteoarthritis deformans. In some there is actually a grating of one or other of the large joints and often of the 
temporo-maxillary articulation. These are, I believe, neither more nor less than cases of osteo-arthritis manifesting itself in the stapediovestibular joint. From what I gather from physicians, deafness is not unfrequent in the subjects of this disease. In many cases sclerosis of the middle ear starts as the result of pregnancy and gets worse after each confinement. This history, in any given case, would suggest that the chronic ear disease is sclerotic in nature. In other cases, syphilis or gout may form the foundation of the trouble. Politzer considers Gradenigo's opinion that it is often a result of an otherwise latent hereditary specific dyscrasia well founded.

\section{'Stapedectomy and other middle-ear operations', C J Blake (1893)}

Reporting on a meeting of the American Otologic Society, this paper ${ }^{2}$ is one of the earliest discussions of the merits and risks of stapedectomy:

During the past year the author had investigated the question of the possibility and advisability of the extraction of the stapes in chronic nonsuppurative disease of the middle ear. As a result of the investigation the following conclusions seemed justified: That in those cases of nonsuppurative disease of the middle ear, with a high degree of deafness, the operation of stapedectomy is most likely to be futile, because of the degree of fixation of the base of the stapes, leading to fracture of the crura in the attempts at removal. That in the class of cases where stapedectomy has apparently given the best results, viz., fixation of the stapes as a sequence of chronic suppurative disease, it is by no means certain that equally good results could not have been obtained by surgical mobilization and subsequent care. That while removal of the stapes is by no means so hazardous a procedure, it still opens up the possibility of interference to an unknown degree with the most important part of the organ of hearing, and an almost equally important peripheral organ of equilibrium. The speaker prefers, when possible, in cases of non-suppurative disease of the middle ear, to begin with exploratory tympanotomy, which is an operation without general anaesthesia, leaving it to be determined by the examination and tests made during the operation as to whether the stapes can or shall be removed or not.

\section{'Remarkable improvement in hearing following removal of the stapes', F L Jack (1892)}

In 1892, a year earlier than Blake's report, F L Jack of Boston presented a series of such procedures: ${ }^{3}$

He had recently operated on a case of chronic suppurative otitis in a girl aged twelve. After removing portions of the membrana tympani, malleus, and incus, examination showed the head of the stapes to be carious, and it was decided to remove the bone. Previous to operation there was very little hearing in the affected ear. On the following morning the hearing was much better, and this fact suggested the possibility of good results from the removal of the stapes. Previous to this the speaker had operated on two cases of chronic non-suppurative middleear inflammation, by removal of the drum membrane, malleus, and incus. The results, as regards hearing, were not satisfactory. Removal of the stapes is much better in its results, and in the author's experience there had been no inflammatory reaction whatever. The method of operating was then described. Sixteen cases were reported in detail, giving the results of tests for hearing before and after operation. Two of the cases were presented to the Society for examination. The effect of the operation on the hearing, as tested by the watch, in some was not marked in either way, in others there seemed to be a slight loss, and in others again a slight gain.

\section{'Observations on the removal of the stapes', F L Jack (1893)}

By the following year, Jack was able to report on further results, ${ }^{4}$ which could only be described as 'mixed'.

Since bringing the matter before the Society last year, the operation had been tried in thirty-two additional cases. These, with the sixteen previously reported, furnish forty-eight cases for observation and study. In reviewing the cases there is much to encourage the adoption of the procedure, but its clinical application will require modification.

The following conclusions were presented :-

1. The operation is followed by the best results in the class of cases where, from the increase of time, the effects of suppuration, or hypertrophic inflammation, the stapes offer an obstruction to sound-waves; by its removal the hearing is improved. The results in cases of otitis media chronica insidiosa, on account of failure to extract the foot-plate, are not encouraging.

2. Inflammatory reaction is unusual, and followed by no bad results.

3. The hearing is not necessarily impaired by the subsequent growth of a thin cicatricial membrane over the fenestral niche.

4. Some cases of tinnitus and aural vertigo are relieved, and there is little chance of causing permanent vertigo in cases where it had not previously existed.

5. It rarely happens that a patient improves for all tones. Improvement in hearing the human voice 
was out of proportion to the improvement for other sounds, and the reverse sometimes occurred.

6. Failure of success in some cases may be due to haemorrhage into the labyrinth at the time of the operation. It is believed to be a rare complication, but was thought to have occurred in one or two cases.

7. In removing the various ossicles, the stapes, if found diseased, should also be removed.

Lest the reader feel that our predecessors, over a century ago, were universally enlightened on the question of stapes fixation and surgery, it is illuminating to read, in the following two excerpts, that an immobile stapes need be of no clinical significance, and that ossicular surgery is to be recommended for Ménière's disease symptoms.

\section{'The preservation of hearing in spite of fixation of the stapes', E Waggett (1897) \\ With regard to acute hearing, the mobility of the stapes is a matter of great importance, but it is not a sine qua non. Loss of mobility means the loss of accommodation and protection by the tym- panic muscles, and does not mean the loss of hearing. It is, indeed, not rare to find patients with complete fixation of both stapes, who, never- theless, retain sufficient hearing power for the ordinary purposes of conversation. As long, in fact, as the foot-plate retains the configuration}

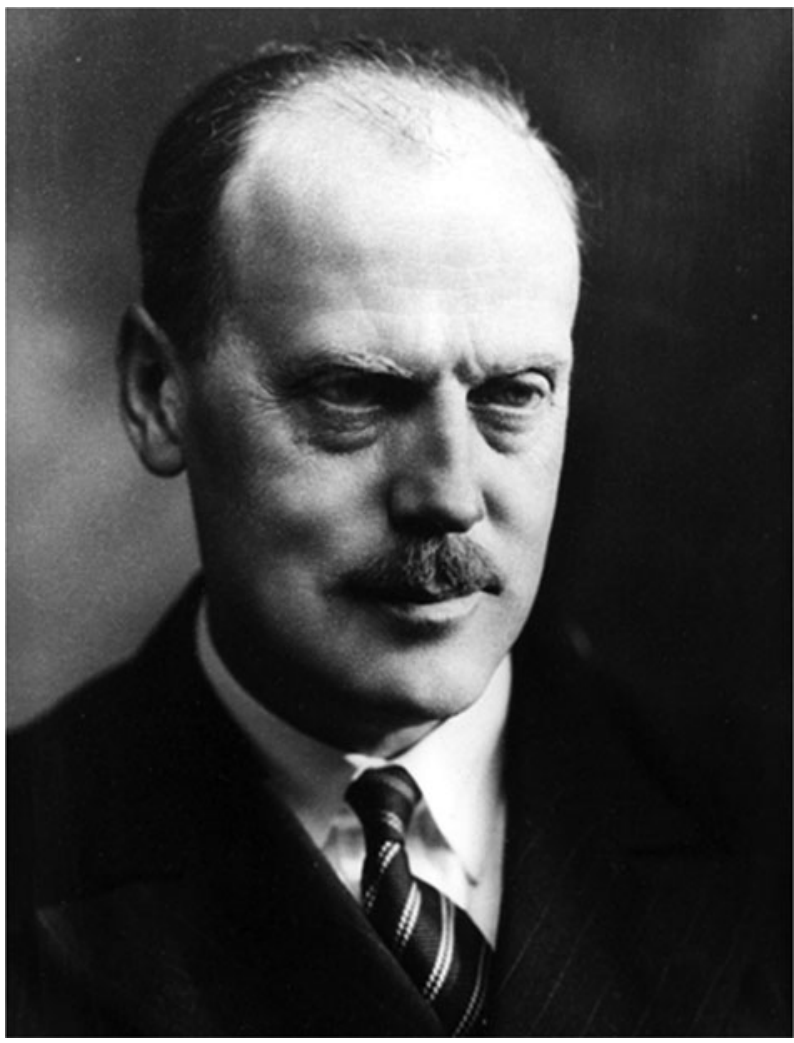

FIG. 1

Ion Simson Hall. of a thin plate, and does not become transformed into a solid mass, while the nerve apparatus remains intact, so long will speech be heard. This fact may often be observed in certain cases of hereditary, bilateral, gouty ankylosis. Both experiment and clinical experience show that the notion that ankylosis means complete deafness is unfounded.

The author deduces:-

(a) That Helmholtz's theory of the conduction of sound by oscillation of the total mass of the stapes, and not by the propagation of the molecular vibration of the transmitting apparatus, is incorrect.

(b) From the surgical point of view we must be prepared to find something besides mere fixation in cases of severe deafness, and must not be surprised with the unsatisfactory results of operations for mobilization. The abuse of politzerization may do much harm by loosening the cohesion of the links of the conductive chain. ${ }^{5}$

\section{'The British Laryngological, Rhinological and Otological Association Proceedings', G Stoker (1895)}

In reply to Dr. Law's query as to the desirability of extraction of the stapes for Meniere's symptoms, I have no experience to offer, but I have found in the few cases in which patients have come under my care on account of vertigo that milder means have sufficed. Moreover, in some of the reported cases of stapedectomy the operation has been credited with setting up vertigo. Extraction of the incus or section of its long process is probably the most justifiable surgical procedure. $^{6}$

'Fenestration of the labyrinth', I S Hall (1945) Fenestration was well established by 1945 , when I Simson Hall (Figure 1) reported his experience of Lempert's operation. ${ }^{7}$ Hall's paper is worth reading if only to see the illustrations of the equipment used. He writes:

About nine years ago, when the series under review was commenced, equipment was primitive. A scraper, usually a mastoid gouge or some such instrument, was used to make the opening in the labyrinth capsule, magnification was negligible, and the operation, under these handicaps, took a very long time. To-day, magnification is obtained by the use of a dissecting microscope [and]... an elaborate set of dental drills... . The operating field is kept clear of blood and debris by an irrigating apparatus which can be used either intermittently or continuously as desired.

Even so, the success rate was very different to that expected from modern otosclerosis surgery. Hall reported 71 cases, and concluded that '... the 
percentage of success over all cases operated upon is 54.9 per cent'.

He also reported that:

Improvement in hearing varies in individual cases from five decibels to thirty decibels over the speech range of frequencies, and in a favourable case, twenty-five to thirty decibels may be expected at the optimum period.

Hall also commented that '...the minimum improvement must be in the region of ten decibels'.

\section{'Fenestration: a twenty-five-year evaluation', D N Brooks (1985)}

Forty years later, Brook's paper $^{8}$ concluded that long-term results were worthwhile. A 25-year follow up of 28 patients (from an original cohort of 58) showed that:

... of these[,] three still had hearing above the social adequacy level of $30 \mathrm{db}$. HL. One half had hearing that was still significantly better than it had been prior to surgery. Twenty-five years postoperatively more than half the patients were using hearing aids, generally with a high degree of satisfaction. Four out of five patients indicated that with hindsight they would still have gone ahead and had the operation.

\section{'Improved hearing after mobilization of the stapes in otosclerotic deafness', S Rosen \& M Bergman (1955)}

Rosen had reported mobilisation of the stapes in 1952, and in this 1955 paper $^{9}$ (with Bergman) concluded:

(i) That the stapedial footplate can be mobilized by the technique here described; (2) that when the stapedial footplate is mobilized the hearing improves markedly; and (3) that the marked hearing improvement has persisted for periods up to two and a half years. It would seem, therefore, that this simple procedure should take place prior to fenestration. Hearing has been restored by fenestration after mobilization has failed. Conversely, hearing has been restored by mobilization after fenestration has failed. A patient deafened by clinical otosclerosis now has a greater chance to recover useful hearing than before. Some patients completely unsuitable for fenestration... may be fruitfully restored to enjoyable use of a hearing aid by mobilization of the stapedial footplate.

\section{'Rosen mobilization of the stapes: does it have a place in modern otology?', \\ G Thiel \& R Mills (2006)}

The role of mobilisation has not been totally discounted following the advent of footplate surgery, as was shown as recently as $2006^{10}$ in two patients. In the first patient: ... the risks associated with stapedectomy were considered to be unacceptable. The favourable outcome in this case of presumed congenital fixation can be attributed to the fact that the disease process causing the fixation was not active.

In the second patient:

... the problem was difficult surgical access. It was considered that a stapedectomy carried an unacceptable risk in these circumstances, and a minimally invasive approach, which would not make a later revision impossible, was thus chosen.

\section{'Footplate surgery in otosclerosis', H P House (1962)}

The advent of stapedectomy obviously transformed the outlook for the patient with otosclerosis, and early techniques rapidly evolved. Howard House (Figure 2), a pioneer in the field, gave the following description. ${ }^{11}$

Present Techniques. I have used one of four procedures to establish continuity of the incus and the oval window following removal of the footplate.

(1) Vein graft with polyethylene strut (Shea).

(2) Fat plug on wire (Schuknecht).

(3) Vein plug on wire (Kos).

(4) Gelfoam wire plug and gelfoam wire knot (House).

An analysis of these various techniques revealed the results to be analogous. The use of a wire over gelfoam eliminates the contamination

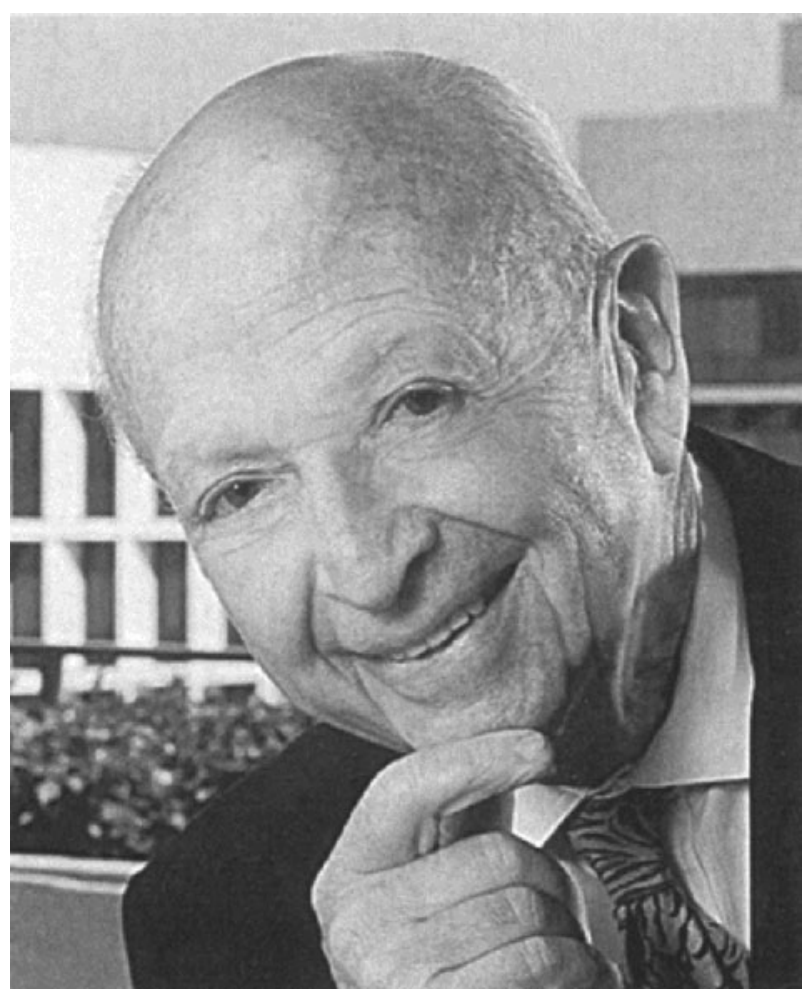

FIG. 2

Howard House. 
hazard of additional external incision necessary to obtain fat or vein and allows prefabrication and sterilization of the prosthesis.

House could report a vast series, with:

... results of the 4 month hearing test in 3,500 primary stapes operations performed during the past 5 years. Very little improvement in results occurred during the first three years in spite of magnification and changes in technique. After introduction of the polyethylene strut and later the wire plug prosthesis, a gradual improvement occurred. Our latest group of 50 cases show closure of the bone-air gap within 10 decibels of the preoperative bone conduction level occurring in 80 to 85 per cent, of the cases at the 4 month hearing test.

It is always easy to be wise in retrospect. However, we can see from the above accounts that some false trails were followed before modern techniques, and a better understanding of otosclerosis, began to evolve.

Doubtless, readers of the future may well scoff at papers on surgery of the endolymphatic sac, tonsil removal, or even the placement of tubes into the tympanic membranes of children. If we are not doomed to repeat its mistakes we should learn from history, and the JLO Archives are a valuable resource in this regard. We hope readers will enjoy the thoughts of those who have gone before us, albeit sometimes flawed, and will remember the saying about 'standing on the shoulders of giants'.

Liam M Flood

Guy Kenyon

Editors

\section{References}

1 Grant D. The varieties of chronic non-suppurative disease of the middle ear. The Journal of Laryngology, Rhinology and Otology 1903;18:234-45

2 Blake CJ. Stapedectomy and other middle-ear operations. The Journal of Laryngology, Rhinology and Otology 1893;7:610

3 Jack FL. Remarkable improvement in hearing following removal of the stapes. The Journal of Laryngology, Rhinology and Otology 1892;6:551

4 Jack FL. Observations on the removal of the stapes. The Journal of Laryngology, Rhinology and Otology 1893;7:611

5 Waggett $\mathrm{E}$. The preservation of hearing in spite of fixation of the stapes. The Journal of Laryngology, Rhinology, and Otology 1897; 12;288-91

6 Stoker G. The British Laryngological, Rhinological and Otological Association Proceedings. The Journal of Laryngology, Rhinology, and Otology 1895;9:876-95

7 Hall IS. Fenestration of the labyrinth. J Laryngol Otol 1945;60: 200-15

8 Brooks DN. Fenestration: a twenty-five-year evaluation. J Laryngol Otol 1985;99:225-30

9 Rosen S, Bergman M. Improved hearing after mobilization of the stapes in otosclerotic deafness. J Laryngol Otol 1955;69: 297-308

10 Thiel G, Mills R. Rosen mobilization of the stapes: does it have a place in modern otology? J Laryngol Otol 2006;120:1067-71

11 House HP. Footplate surgery in otosclerosis. J Laryngol Otol 1962;76:73-86 